\title{
Assessment of the El-Mahmoudia canal, Egypt up to the year 2017
}

\author{
H. M. Moghazy ${ }^{1}$, O. K. Saleh ${ }^{2} \&$ E. H. Ouda ${ }^{3}$ \\ ${ }^{1}$ Faculty of Engineering, Alexandria University, Egypt \\ ${ }^{2}$ Department of Water and Water Structures Engineering, \\ Faculty of Engineering, Zagazig University, Egypt \\ ${ }^{3}$ General Directorate of Irrigation Improvement Projects, Egypt
}

\begin{abstract}
Egypt is exposed to serious water problems as the per capita share of water in Egypt is continuously declining. It has become below the water poverty limit that was determined according to international standards with 1000 cubic meters /capita/year. El-Mahmoudia canal is considered one of the most important canals in the West Delta of Egypt. It is expected to pass extra discharge in the canal during the next years to face the future demands for people. The main objective of the present study is to investigate the hydraulic analysis of El-Mahmoudia canal up to the year 2017. It was studied by applying different expected discharges up to the year 2017. The analysis includes velocities, bed shear stresses, and water levels. The stability of the canal cross-sections was also investigated at three reaches along the canal. A comparison between field and calculated water levels was presented and good agreements were obtained. The CCHE2D-Model was used in this research to simulate flow in the studied canal at different discharges.

Key Words: El-Mahmoudia canal, Egypt, CCHE2D numerical model, canal stability, bed shear stresses.
\end{abstract}

\section{Introduction}

The Nile River is considered as the main source of fresh water in Egypt. According to the agreement of Nile water with Sudan in 1959, the annual share of Egypt from river water is fixed at 55.5 milliard cubic meters. On the other hand, the population is continuously increasing. Thus the capita share of water is 
continuously declining. It was 2135 cubic meters/capita/year in 1960, and then reached 670 cubic meters/capita/year in the year 2011. This means that the present capita share become below 1000 cubic meters/capita/year which present the water poverty limit according to international standards. This value may drop to500 cubic meters/capita/year in 2025. From this point, saving of water becomes very important. El-Mahmoudia canal is one of the most important canals which are fed from Nile River. It is considered as the sole source of irrigation water, municipal and industrial water for Alexandria and Behaira governorates. It serves a gross area of about 150,000 acres. The main objective of this paper is to evaluate the hydraulic parameters of El-Mahmoudia canal to pass extra discharge. The analysis includes velocities, shear stresses, and water levels. Moghazy [1] presented technical report about the design of protection works for El-Mahmoudia canal slopes and banks. Mott Macdonald [2, 3] presented a report about El-Mahmoudia canal including a review of the various control structures, outlet structures, bridges and other structures using ISIS software. Numbers of river engineering studies were successfully conducted using CCHE2D model. Negm et al. [4] studied the velocity distribution in high Aswan dam reservoir, Egypt using CCHE2D simulation model. Saleh [5] studied the effect of abstracting water from Tana River in Kenya through constructing a side canal with gravity intake on the sediment transport behavior, longitudinal, lateral velocity components and longitudinal, lateral average velocity in Tana River upstream the side canal location using CCHE2D - model. Several studies were done on El-Mahmoudia canal. ACCHE-2D finite element model which was developed by NCCHE National Center for Computational Hydro Science and Engineering (Zhang [6]).

\section{Numerical model}

CCHE2D model is an integrated package for simulation and analysis of free surface flows, sediment transport and morphological processes. It was developed by NCCHE National Center for Computational Hydro science and Engineering [6]. The inputs for CCHE2D_Mesh Generator are one of these forms: Topography data base, the measured survey cross-sections or Topographical map. The outputs from CCHE-2D Mesh generator are: the mesh that generated by using the algebraic and the numerical methods, levels at all points of mesh after doing interpolation for levels given in data base and sections in horizontal and longitudinal directions.

\section{Description of the canal}

It has a length of $77.100 \mathrm{~km}$ and it serves an area of about 150,000 acres (as shown in Fig. 1). It is fed from four sources: the main source is El-Atff Pump station, Edko Pumping station, El-Khandaq El-Sharqi canal, and small re-use pumping stations feeding tail ends on some branch canals. El-Mahmoudia canal suffers from many problems such as illegal buildings on berms and vegetations 


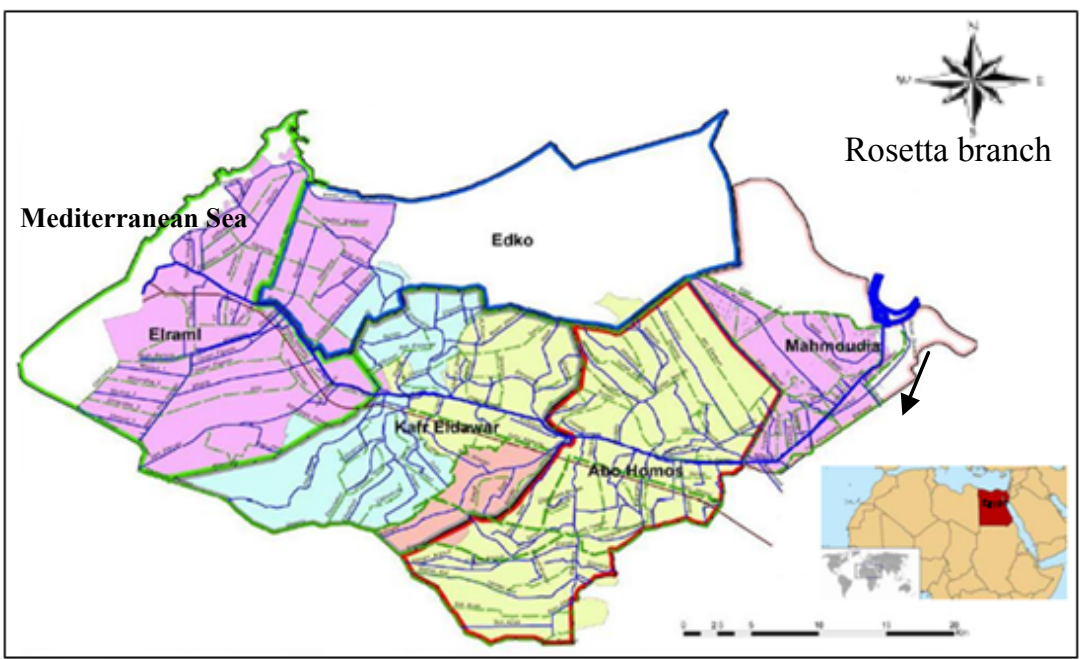

Figure 1: The branch canals network of the El-Mahmoudia command area, Egypt, [3].

along the side slopes. These problems obstruct any widening of the canal in the future.

\section{Analysis of results}

Table 1 lists the discharges of El-Mahmoudia canal from different sources. Therefore, different proposed discharges were applied into El-Mahmoudia canal to face the future demands for people up to the year 2017.Theses discharges were

Table 1: The discharges of El-Mahmoudia canal from different sources up to the year 2017 [4].

\begin{tabular}{|c|c|c|}
\hline Source of water & $\mathrm{Km}$ & $\begin{array}{c}\text { Proposed } \\
\text { discharge } \\
\text { Year 2017 } \\
\left(\mathrm{Mm}^{3} / \text { day }\right)\end{array}$ \\
\hline $\begin{array}{c}\text { El-Atff pumping } \\
\text { stations }\end{array}$ & 0.300 & 13 \\
\hline $\begin{array}{c}\text { Edko re-use } \\
\text { pumping station }\end{array}$ & 8.850 & 1 \\
\hline $\begin{array}{c}\text { El-Khandaq } \\
\text { El-Sharqi canal }\end{array}$ & 15.170 & 2.7 \\
\hline Total & & 16.7 \\
\hline
\end{tabular}


applied to the computer program CCHE2D - model. Three reaches were selected in the curved reaches to check their hydraulic properties and to check their stability against flooding. Velocity, bed shear stress, bed levels and water levels were also investigated. Table 2 lists the locations of the proposed reaches.

Table 2: $\quad$ Locations of the studied reaches along El-Mahmoudia canal.

\begin{tabular}{|c|c|c|}
\hline Reach No & From Km & To Km \\
\hline 1 & 2.550 & 4.520 \\
\hline 2 & 13.200 & 15.000 \\
\hline 3 & 28.050 & 33.700 \\
\hline
\end{tabular}

\section{Velocities}

Figures 2 and 3 show values of average velocities obtained from the program results at different sections. It can be noticed that all the velocity values were within the allowable range for earthen canal $(0.6-0.8 \mathrm{~m} / \mathrm{sec})$ at left and right sides at all of sections. However, it can be observed that velocities have higher value exceed than $0.8 \mathrm{~m} / \mathrm{sec}$ in the centre line of the canal at all sections of reach No. (2) and most of sections of reach No. (4). accordingly, it is expected to have erosion problem in canal bed at these sections.

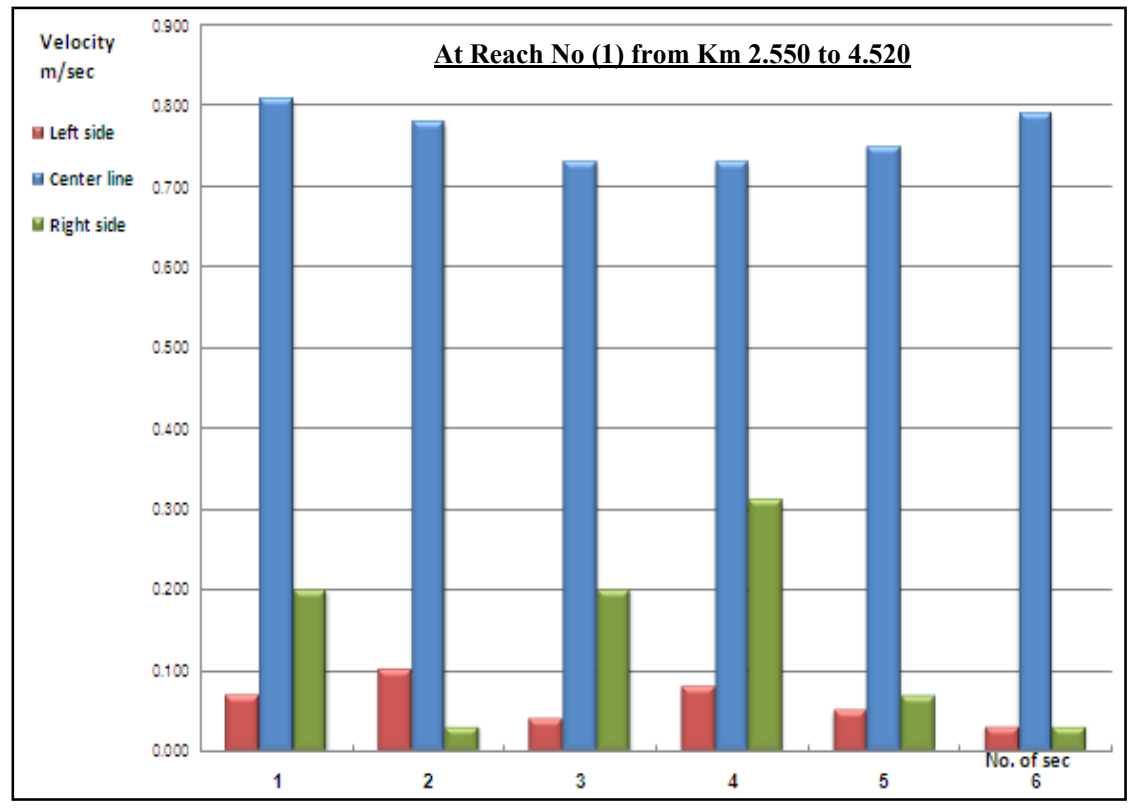

Figure 2: $\quad$ Results of average velocities at reach No. (1), year 2017. 


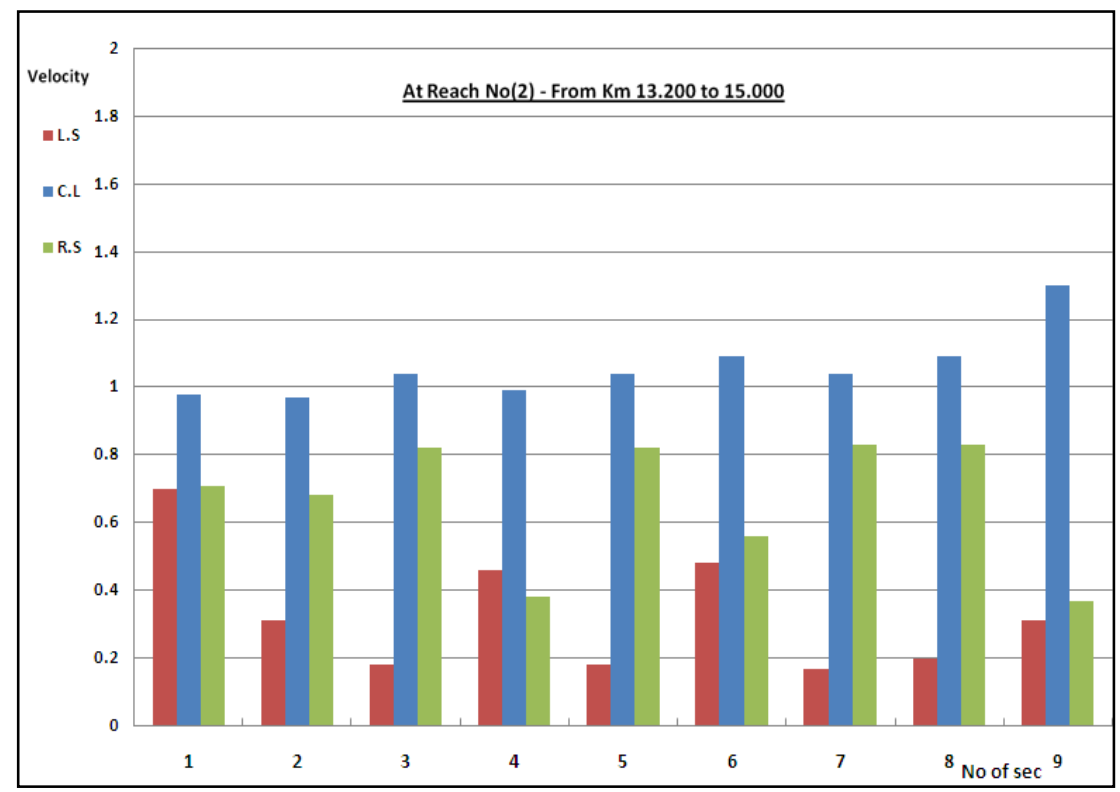

Figure 3: $\quad$ Results of average velocities at reach No. (2), year 2017.

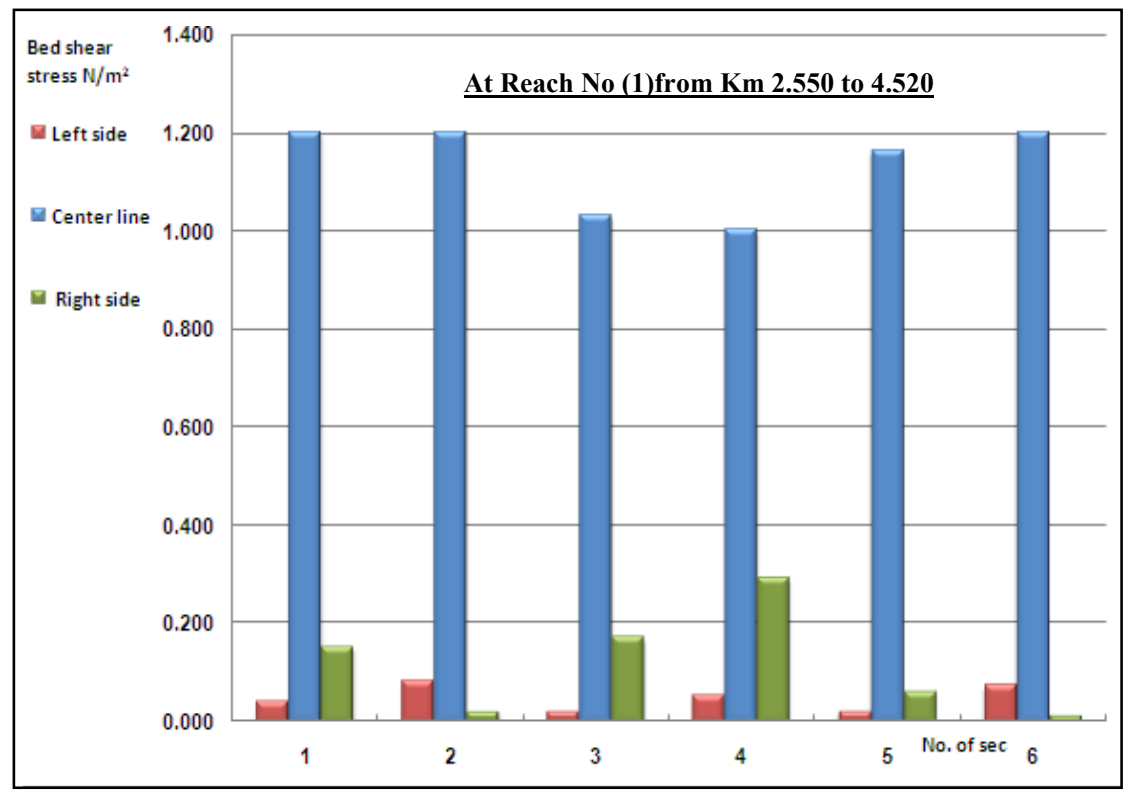

Figure 4: $\quad$ Results of bed shear stresses at reach No. (1), year 2017. 


\section{Bed shear stresses}

Figures 4 and 5 show the results of the bed shear stresses for the five reaches. It is clear that the shear stresses values increase at the bed near the center line more than banks. The values of bed shear stresses were higher than the average value $\tau_{\circ}=1.37 \mathrm{~N} / \mathrm{m}^{2}$ at $\mathrm{km} 4.250$ of reach No.3 and all the sections of reaches No. 2 and 4 . These cross sections are expected to be unstable and erosion process is expected at these sections especially at the bed near canal center line.

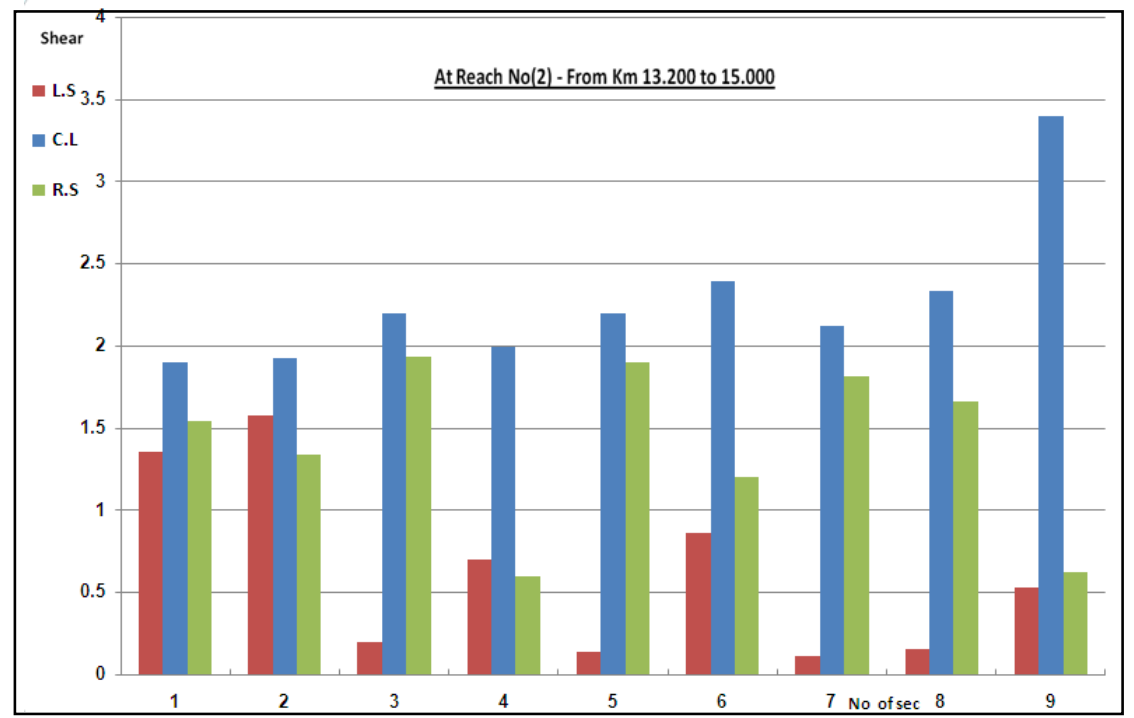

Figure 5: $\quad$ Results of bed shear stresses at reach No. (2), year 2017.

\section{Conclusions}

According to the present study at three reaches of El-Mahmoudia canal, Egypt, the main conclusions can be summarized as follows:

1) The numerical model CCHE2D is a flexible tool to evaluate the hydraulic analysis of the open channels. It gives good results compared with the field water levels measurements.

2) In the studied reaches, most of water velocities are within the acceptable range in both sides of canal, while at the centre line, some sections in canal have higher velocities than the allowable limits for earthen canals.

3 ) In the studied reaches, most of bed shear stresses values at the centre line of the canal were higher than the calculated mean value, while at both sides of the canal they were less than the calculated value at most of sections.

4) Protections to unsafe sections are needed to overcome flooding problems along the canal. Embankment levels should be elevated at these sections by earth 
filling to get safe sections. Sheet piles or gabions can also be used to protect canal side slopes.

\section{References}

[1] Moghazy, H. M ,"Technical report about design of protection works of sides and embankment of El-Mahmoudia canal from the intake to km 16.000", Technical report, Horizontal Expansion Sector, Ministry of Water Resources and Irrigation (2007).

[2] Mott MacDonald, Subbor, "Design and Rehabilitation of Main canals Mahmoudia canal", Inception report, Ministry of Water Resources and Irrigation, September (2009).

[3] Mott MacDonald, Subbor, "Design and Rehabilitation of Main Canals", Technical Report, Ministry of Water Resources and Irrigation, July (2010).

[4] Negm, A. M., Abdulaziz, T. and Fathy, I "Predication of velocity distribution in high Aswan dam reservoir using CCHE2D simulation model" (2009).

[5] Saleh, O. K., "Sediment transport in Tana River upstream of proposed Gravity Intake", Ain Shams Journal of Civil Engineering pp. 281-292, September (2009).

[6] Zhang, Y. "CCHE2D-GUI-Geographical user Interface for the CCHE2D Model”, User's Manual, version 2.2, Technical report No. NCCHE-TR2005-03, University of Mississippi, May (2005).

[7] Zhang, Y. and Jia, Y., "CCHE-2D Structured Mesh Generator", User's Manual, version 3.x, Technical report No. NCCHE-TR-2009-01, University of Mississippi, February (2009). 